\section{KẾT LUÂN}

Tắc ruột quai đóng là một cấp cứu ngoại khoa. Vì vậy, điều quan trọng là phải nhận diện được các dấu hiệu trên CLVT của tắc ruột quai đóng bao gồm dấu hiệu có ít nhất hai điểm chuyển tiếp, mỏ chim, quai ruột hình chữ $U / C$, dấu hiệu "vành tia", cuộn xoáy và vị trí bất thường của quai ruột. Thành ruột ngấm thuốc kém và mach máu mạc treo ngấm thuốc kém là các dấu hiệu chỉ gợi ý cho thiếu máu thành ruột.

\section{TÀl LIÊU THAM KHẢO}

1. Hà Văn Quyết. Bài giảng bệnh học tắc ruột. Nhà Xuất Bản Y Hoc

2. Balthazar EJ, Birnbaum BA, Megibow AJ, Gordon RB, Whelan CA, Hulnick DH. Closedloop and strangulating intestinal obstruction: CT signs. Radiology. 1992;185(3):769-775.

3. Maglinte $D$, Herlinger $H$, Nolan $D$ (1991) Radiologic features of closed loop obstruction: analysis of 25 confirmed cases. Radiology 179:383-387
4. Elsayes KM, Menias CO, Smullen TL, Platt JF Closed-Loop Small-Bowel Obstruction: Diagnostic Patterns by Multidetector Computed Tomography. J Comput Assist Tomogr. 2007;31(5):5.

5. Makar RA, Bashir MR, Haystead $C M$, et al. Diagnostic performance of MDCT in identifying closed loop small bowel obstruction. Abdom Radiol. 2016;41(7):1253-1260.

6. Nakashima $K$, Ishimaru $H$, Fujimoto $T$, et al. Diagnostic performance of CT findings for bowel ischemia and necrosis in closed-loop small-bowel obstruction. Abdom Imaging. 2015;40(5):10971103.

7. Nguyễn Văn Khánh. Đánh giá giá trị cuẩ cắt lớp vi tính đa dãy trong chẩn đoán một số nguyên nhân tắc ruột cơ giới. Đại Học Y Hà Nội; 2019

8. Millet I, Taourel P, Ruyer A, Molinari N. Value of CT findings to predict surgical ischemia in small bowel obstruction: A systematic review and metaanalysis. Eur Radiol. 2015;25(6):1823-1835.

9. Ha H. K., Park C. H., Kim S. K., et al. (1993), "CT analysis ofintestinal obstruction due to adhesions: early detection of strangulation". JComput Assist Tomogr, 17 (3), pp. 386-389.

\title{
ĐĂC ĐIỂM LÂM SÀNG RỐI LOẠN TRẦM CẢM Ở NGƯờI BÊ̂NH VẢY NẾN ĐIỀU TRI TẠI BỆNH VIỆN DA LIỄU TRUNG ƯO'NG
}

\section{TÓM TẮT}

Đặt vấn đê: Trâm cảm là bệnh lý đi kèm thường găp ở người bệnh vảy nến, trâm cảm làm triệu chứng vày nến nă̆ng hơnn, biến chứng xảy ra nhiều hơn, giảm tuân thủ điều trị, tăng nguy cơ tử vong và tư sát trên người bệnh. Mục tiêu nghiên cứu: Mô tả đặc điểm lâm sàng rối loạn trầm cảm ở người bệnh vảy nến điều trị nội trú tại bệnh viện Da Liễu Trương Ương. Đối tượng và phướng pháp nghiên cứu: Nghiên cứu mô tả cắt ngang 122 người bệnh vảy nến điều trị tai bênh viên Da Liểu Trung Ương từ tháng 08/2020 đến tháng 08/2021. Kết quả: Đối tượng nghiên cứu bệnh nhân nam nhiêu hơn bệnh nhân nữ chiếm tỷ lệ $68,9 \%$ so với nữ là $31,1 \%$; độ tuổi trung bình $51,02 \pm$ 15,79 ; nơi sinh sống chủ yếu ở nông thôn $(55,7 \%)$; trình độ học vấn trung học phổ thông (41\%). Có $26,2 \%$ người bệnh có rối loạn trầm cảm theo ICD 10 , trong đó trầm cảm nhẹ chiếm 13,9\%; triệu chứng khởi phát hay gặp nhất tự ti $(46,9 \%)$; trong các triêu chứng đặc trưng đặc trưng của trâm cảm, khí sắc

\footnotetext{
${ }^{1}$ Đại học Y Hà Nội

2Viện sức Khỏe Tâm thần, Bệnh viện Bạch Mai

Chịu trách nhiệm chính: Phạm Thị Thu Hà

Email: hajapan94@gmail.com

Ngày nhận bài: 26.7.2021

Ngày phản biện khoa học: 27.9.2021

Ngày duyệt bài: 6.10.2021
}

\section{Phạm Thị Thu Hà', Nguyễn Doãn Phương ${ }^{2}$, Nguyễn Văn Tuấn ${ }^{1,2}$, Lê Công Thiện ${ }^{1,2}$,}

trâm là hay gặp nhất $(96,9 \%)$; trong các triệu chứng phổ biến của trầm cảm, hay gặp nhất là giảm tính tự trọng và lòng tự ti $(100 \%)$ và rối loạn giấc ngủ $(90,6 \%)$. Kết luận: Trầm cảm thường khởi phát đâu tiên bởi tự ti về bản thân. Triệu chứng đặc trưng hay gặp nhất là khí sắc trầm, triệu chứng phổ biến hay gặp là giảm sút tính tự trong, lòng tự tin và rối loạn giấc ngủ.

Tư khóa: trầm cảm, vảy nến, đặc điểm lâm sàng.

\section{SUMMARY}

\section{CLINICAL FEATURES OF DEPRESSION IN PATIENT WITH PSORIASIS TREATMENT AT NATIONAL DERMATOLOGY HOSPITAL}

Background: Depression is a common comorbid disease in psoriasis patients, which adversely affects the patients' physical and mental aspects. Depression makes psoriasis symptoms worse, decreases treatment adherence, increases complications rates, mortality and suicide rates. Objectives: To describe clinical features of depression in patients with psoriasis. Subjects and research methods: A cross-sectional descriptive study of 122 patients with psoriasis who were treated at the National Hospital of Dermatology from August 2020 to August 2021. Results: Male and female ratio is about 2:1; average age is $51 \pm 15.79$; living in rural areas $55.7 \%$; upper secondary education level - $41 \%$. Main clinical features: $26.2 \%$ of patients with depressive 
disorders, (13,9\% mild level) according to ICD-10 criteria; the most common onset symptom is low selfesteem (46.9\%); depressed mood (96,9\%); low selfesteem, self-confidence - $100 \%$; sleep disturbances $(90,6 \%)$. Conclusion: Depression in psoriasis patients often starts with low self-esteem, selfconfidence. The most common symptom is depressed mood, other popular symptoms are low self-esteem, self-confidence and sleep disturbances.

Keywords: depression, psoriasis, clinical features.

\section{I. ĐĂT VẤN ĐỀ}

Bệnh vẩy nến là một bệnh mạn tính, tái phát, qua trung gian miễn dịch thường găp ở da và khớp, tác động tiêu cực đáng kể đển thể chất, tình cảm và tâm lý xã hội của người bệnh ${ }^{1}$. Bệnh vảy nến chiếm tỷ lệ khoảng 2-3\% dẩn số trên thế giới ${ }^{2}$. Cơ chế bệnh sinh chưa rõ ràng, tuy nhiên thường gặp ở những người có sẵn yếu tố di truyền, miễn dịch, khởi phát dưới tác động yếu tố thuận lợi như chấn thương, nhiễm khuẩn khu trú, stress.

Trầm cảm là một trạng thái của cảm xúc biểu hiện bằng ức chế toàn bộ các hoạt động tâm thần: chủ yếu ức chế cảm xúc, ức chế tư duy, ức chế vận động ${ }^{3}$. Trầm cảm là một rối loạn tâm thần thường gặp của bệnh vảy nến. Tỷ lệ trâm cảm ở bênh nhân vảy nến được ước tính từ $19,2 \%$ đến $62 \%$ theo các nghiên cứu khác nhau ${ }^{4}$ theo từng nghiên cứu khác nhau. Theo Darko Biljan và CS năm 2009 tỉ lệ rối loạn trầm cảm ở bệnh nhân vảy nến là $19,2 \%{ }^{5}$. Theo một nghiên cứu mô tả cắt ngang của Schmitt J và CS năm 2007 trong số 265 bệnh nhân vẩy nến, có $32 \%$ bệnh nhân trầm cảmó . Bệnh vảy nến ảnh hưởng nhiều đến công việc, chẩt lượng cuộc sông đặc biêt là tâm lý người bênh do triệu chứng bênh biểu hiện chủ yếu là trển da làm cho bệnh nhân bị kì thị, dẫn đến có nhiều phản ứng tiêu cực như xấu hổ, bối rối, tự ti, mắc cảm, thâm chí có thể có ý tưởng và hành vi tự sát. Với những hậu quả nghiêm trọng mà trầm cảm gây ra trên bệnh vảy nển, việc phát hiện và điều trị sớm trầm cảm có ý nghĩa quan trọng trong giảm triệu chứng, làm giảm tiến triển của bệnh, cải thiện chất lượng cuộc sống, giảm tỷ lệ tử vong, giảm gánh nặng cho gia đình và xã hội.

Trầm cảm trên bênh vảy nến đã được nghiên cứu rộng rãi ở nhiều nước trên thế giới, tuy nhiên, tại Việt Nam vấn đề này còn chưa được chú trọng nên việc chẩn đoán và điều trị còn hạn chế và thường bệnh nhân được khám hoặc hội chẩn chuyên khoa tâm thần thường muộn. Do đó, chúng tôi tiến hành đề tài: "Đặc điểm lâm sàng rối loạn trầm cảm ở người bệnh vảy nến điều trị nội trú tại bệnh viện Da Liễu Trung
Ương" với mục tiêu sau: "Mô tả đặc điểm lâm sàng rối loạn trầm cảm ở người bệnh vảy nến điều trị tại bệnh viện Da Liễu Trương Uơng".

\section{II. ĐỐI TƯƠNG VÀ PHƯƠNG PHÁP NGHIÊN CỨU}

2.1 Đối tượng nghiên cứu: 122 người bệnh vảy nến điều trị tại bệnh viện $\mathrm{Da}$ Liễu Trung Ương từ tháng 08/2020 đến tháng 08/2021.

Tiêu chuân lựa chọn: Người bệnh đồng ý tham gia nghiên cứu.

Tiêu chuẩn loại trừ: Người bệnh có bệnh cơ thể nặng kèm theo hạn chế khả nắng giao tiếp.

2.2 Phương pháp nghiên cứu: Phương pháp mô tả lâm sàng cắt ngang, cõ̃ mẫu thuân tiện. Số liệu được xử lý bằng phần mềm SPSS 20.0

2.3 Đạo đức nghiên cứu: Số liệu được mã hóa nhằm giữ bí mật thông tin cho người bệnh. Đây là nghiên cứu mô tả không can thiệp chẩn đoán và điều trị, không ảnh hưởng đến sức khỏe người bệnh. Người bệnh và người nhà đồng ý tham gia nghiên cứu

\section{KẾT QUẢ NGHIÊN CỨU VÀ BÀN LUÂ̂N \\ 3.1 Đặc điểm chung của nhóm đối tượng} nghiên cứu

Bảng 1. Đặc điểm chung của nhóm đôi tượng nghiên cứu ( $N=122)$

\begin{tabular}{|c|c|c|c|}
\hline \multicolumn{2}{|c|}{ Đặc điếm chung } & \multirow{2}{*}{\multicolumn{2}{|c|}{\begin{tabular}{c|c}
$\mathbf{n}$ & $\%$ \\
\end{tabular}}} \\
\hline & uối trung bình & & \\
\hline \multirow{2}{*}{ Giới } & Nam & 84 & 68,9 \\
\hline & Nữ & 38 & 31,1 \\
\hline \multirow{3}{*}{ Nơi ở } & Nônq thôn & 68 & 55,7 \\
\hline & Thành thi & 47 & 38,6 \\
\hline & Miền núi & 7 & 5,7 \\
\hline \multirow{8}{*}{$\begin{array}{l}\text { Nghề } \\
\text { nghiệp }\end{array}$} & Học sinh-Sinh viên & 3 & 2,5 \\
\hline & Công nhân & 7 & 5,7 \\
\hline & Nông dân & 54 & 44,2 \\
\hline & Kinh doanh & 3 & 2,5 \\
\hline & Cán bô & 6 & 4,9 \\
\hline & Nghỉ hưu & 28 & 23,0 \\
\hline & Thất nghiêp & 1 & 0,8 \\
\hline & Khác & 20 & 16,4 \\
\hline \multirow{5}{*}{$\begin{array}{c}\text { Trình } \\
\text { độ } \\
\text { học } \\
\text { vấn }\end{array}$} & Mù chữ & 1 & 0,8 \\
\hline & Tiếu học & 12 & 9,8 \\
\hline & Trung học cơ sở & 41 & 33,6 \\
\hline & Trung học phố thông & 50 & 41,0 \\
\hline & $\begin{array}{l}\text { Trung cấp, cao đắng, } \\
\text { đại học, sau đại học }\end{array}$ & 18 & 14,8 \\
\hline
\end{tabular}

Nhânn xét: Nghiên cứu của chúng tôi đã thu thập trên 122 đối tượng nghiên cứu, trong đó bệnh nhân nam nhiều hơn bệnh nhân nữ chiếm tỷ lệ $68,9 \%$ so với nữ là $31,1 \%$. Độ tuổi trung bình là $51,02 \pm 15,79$. Kết quả này gần tương 
đồng với nghiên cứu của Lê Thị Hồng Thanh và CS (2021) khi độ tuổi trung bình là 53,97士13,98; tỷ lệ nam giới $(60 \%)$ và nữ giới $(40 \%)^{8}$. Nghế nghiệp phổ biến nhất nông dân chiếm tỳ lệ $44,2 \%$, các đối tượng nghiên cứu chủ yếu sống ở nông thôn (55,7\%), trình độ học vấn được báo cáo nhiều nhất là trung học phổ thông (41\%).

3.2. Đặc điểm lâm sàng rối loạn trâm cảm ở người bệnh vảy nến

\subsubsection{Mức độ trâm cảm theo ICD - 10}

Bảng 2. Mức độ trầm cảm theo ICD - 10 $(N=32)$

\begin{tabular}{|c|c|c|}
\hline \multirow{2}{*}{ Mức Tiêu chộ } & \multicolumn{2}{|c|}{ ICD $\mathbf{- 1 0}$} \\
\cline { 2 - 3 } & $\mathbf{n}$ & $\mathbf{\%}$ \\
\hline Trầm cảm nhệ & 17 & 53,1 \\
\hline Trầm cảm vừa & 8 & 25,0 \\
\hline Trầm cảm nặng & 7 & 21,9 \\
\hline Tống & $\mathbf{3 2}$ & $\mathbf{1 0 0}$ \\
\hline
\end{tabular}

Nhận xét: Tỷ lệ trâm cảm theo ICD - 10 trong nghiên cứu của chúng tôi là $26,2 \%$, trong đó chủ yếu là trầm cảm nhẹ $(53,1 \%)$, tỷ lệ trâm cảm vừa $(25 \%)$ và trầm cảm nặng $(21,9 \%)$, trong đó không có các triệu chứng loạn thần. Kết quả này của chúng tôi tương đồng với nghiên cứu của Chan $F$ và cs (2009) tỷ lệ rối loạn trầm cảm là $26,4 \% 9$.

3.2.2. Triệu chứng khởi phát của tràm cảm Bảng 3. Triệu chứng khởi phát của trâm cám $(N=32)$

\begin{tabular}{|c|c|c|}
\hline Triệu chứng Số lượng & $\mathbf{n}$ & $\mathbf{\%}$ \\
\hline Tự ti & 15 & 46,8 \\
\hline Buồn chán & 8 & 25,0 \\
\hline Mệt mỏi, giảm năng lượng & 4 & 12,5 \\
\hline Mất ngủ & 3 & 9,4 \\
\hline Chán ăn & 2 & 6,3 \\
\hline Tống & $\mathbf{3 2}$ & $\mathbf{1 0 0}$ \\
\hline
\end{tabular}

Nhận xét: Tự ti là triệu chứng khởi phát rối loạn trầm cảm hay gặp nhất ở các đối tượng trong nghiên cứu $(46,8 \%)$. Xếp thứ 2 là buồn chán với $25,0 \%$, tiếp theo là mệt mỏi, giảm năng lượng với $12,5 \%$, một số người bệnh khởi phát trầm cảm với triệu chứng mất ngủ $(9,4 \%)$ và chán ăn $(6,3 \%)$. Vảy nến chủ yếu biểu hiện bệnh trên da dấn đến bệnh nhân cảm thây tự ti về ngoại hình, bị kỳ thị khiến bệnh nhân buồn chán, bi quan về tương lai, bên cạnh đó những biến chứng của vảy nến làm cho người bệnh cảm thây mêt mỏi, mất ngủ và chán ăn là nguyên nhân dấn đến khởi phát triệu chứng về rối loạn cảm xúc trong đó có trầm cảm.

3.2.3. Triệu chứng chính của trâm cảm theo ICD - 10

Bảng 4. Triệu chứng chính của trầm cảm theo ICD - $10(\mathrm{~N}=32)$

\begin{tabular}{|c|c|c|}
\hline Số lượng & $\mathbf{n}$ & $\mathbf{\%}$ \\
\hline Triệu chứng & 31 & 96,9 \\
\hline Khí sắc trầm & 30 & 93,8 \\
\hline $\begin{array}{c}\text { Gất quan tâm năm thích thú } \\
\text { mệt mơợi }\end{array}$ & 28 & 87,5 \\
\hline
\end{tabular}

Nhận xét: Trong số các triệu chứng chính của trầm cảm theo ICD - 10, khí sắc trầm chiếm tỷ lệ cao nhất với 96,9\%. Mất quan tâm thích thú và giảm năng lượng, dễ mêt mỏi cũng chiếm tỷ lệ rất cao lần lượt là $93,8 \%$ và $87,5 \%$. Vảy nến ảnh hưởng nhiêuu đến công việc, chất lượng cuộc sống đặc biệt là tâm lý người bệnh khiến bệnh nhân cảm thấy buồn chán, ủ rũ. Các biến chứng của bệnh vảy nến làm cho bệnh nhân càng cảm thấy mệt mỏi hơn. Người bệnh suy nghĩ, buồn chán bệnh tật bản thân nên không còn muốn quan tâm tới những thú vui, sở thích trước đây.

3.2.4. Triệu chứng phổ biến của trầm cảm theo IC - D10

Bảng 5. Triệu chứng phổ biến của trâm caim theo ICD - $10(N=32)$

\begin{tabular}{|c|c|c|}
\hline Triêu chứng Số lượng & n & $\%$ \\
\hline Giảm tập trung chú ý & 9 & 28,1 \\
\hline $\begin{array}{c}\text { Giảm sút tính tự trọng và lòng tự } \\
\text { tin }\end{array}$ & 32 & 100,0 \\
\hline Y tưởng bị tội và không xứng đáng & 8 & 25,0 \\
\hline Bi quan về tương lai & 19 & 59,4 \\
\hline Y tưởng hoặc hành vi tự sát & 7 & 21,9 \\
\hline Rối loạn giấc ngủ & 29 & 90,6 \\
\hline Àn ít ngon miệng & 17 & 53,1 \\
\hline
\end{tabular}

Nhận xét: Trong số các triệu chứng phổ biến của trầm cảm theo ICD - 10, giảm sút tính tự trọng, lòng tự tin và rối loạn giấc ngủ là hai triệu chứng hay gặp nhất với tỷ lệ lân lượt là $100 \%$ và $90,6 \%$. Các triệu chứng khác lần lượt là bi quan về tương lai $(59,4 \%)$, giảm tập trung chú ý $(28,1 \%)$, ý tưởng bị tội và không xứng đáng $(25,0 \%)$. Đặc biệt nghiêm trọng là triệu chứng về ý tưởng và hành vi tự sát chiếm một tỉ lệ không nhỏ $(21,9 \%)$. Tự sát là một triệu chứng đặc biệt nghiêm trọng và là một cấp cứu chuyên ngành tâm thần. Nhìn chung, các triệu chứng phổ biến hay xuất hiện do bệnh nhân mặc cảm, tự ti về ngoại hình của bản thân. Bệnh nhân cảm thấy xấu hổ, bị kỳ thị nên ngại tiếp xúc với mọi người xung quanh, tự cô lập bản thân.

\section{KẾT LUẬN}

Trầm cảm là rối loạn tâm thần thường gặp ở người bệnh vảy nến $(26,2 \%)$. Trầm cảm thường khởi phát đầu bởi bệnh nhân cảm thây tự ti về 
bản thân mình (46,9\%), triệu chứng đặc trưng hay gặp nhất là khí sắc trầm $(96,9 \%)$, triệu chứng phổ biến hay gặp là giảm sút tính tự trọng, lòng tự tin $(100 \%)$ và rối loạn giấc ngủ $(90,6 \%)$.

\section{TÀl LIỆ THAM KHẢO}

1. Langley RGB, Krueger GG, Griffiths CEM. Psoriasis: epidemiology, clinical features, and quality of life. Ann Rheum Dis. 2005;64 Suppl 2:ii18-23; discussion

ii24-25. doi:10.1136/ard.2004.033217

2. González-Parra $\mathbf{S}$, Daudén $\mathbf{E}$. Psoriasis and Depression: The Role of Inflammation. Actas Dermo-Sifiliográficas (English Edition). 2019;110 (1):12-19. doi:10.1016/ j.adengl.2018.05.035

3. Giáo trình Bệnh học tâm thân Trường Đại Hoc Y Hà Nôi, Giai đoạn trầm cảm trang 54, 2016.

4. McDonough E, Ayearst $R$, Eder $L$, et al. Depression and Anxiety in Psoriatic Disease: Prevalence and Associated Factors. The Journal of
Rheumatology. 2014;41(5):887-896. doi:10.3899/ jrheum.130797

5. Biljan D, Laufer D, Filaković $\mathbf{P}$, Situm $\mathbf{M}$ Brataljenović T. Psoriasis, mental disorders and stress. Coll Antropol. 2009;33(3):889-892.

6. Schmitt JM, Ford DE. Role of Depression in Quality of Life for Patients with Psoriasis. DRM. 2007;215(1):17-27. doi:10.1159/000102029

7. Wu KK, Armstrong AW. Suicidality among psoriasis patients: a critical evidence synthesis. G Ital Dermatol Venereol. 2019;154(1):56-63. doi: $10.23736 / S 0392-0488.18 .06112-6$

8. Lê Thị Hồng Thanh. Nghiên cứu một số yếu tố liên quan và đặc điểm lâm sàng bệnh vảy nến thông thường khám và điều tri tai Bênh viên $\mathrm{Da}$ liễu Trung ương từ tháng $01 / 2018$ đến tháng 12/2018. Journal of 108 - Clinical Medicine and Phamarcy. 2020;15(3). Accessed August 31, 2021. https://tcydls108.benhvien108.vn/index.php/YDLS/ article/view/209

9. Chan F, Ho K, Pang A. Depression in Hong Kong Chinese patients with psoriasis. Hong Kong Journal of Dermatology and Venereology. 2009;17.

\section{TÌNH TRẬ ĐIỀU TRỊ THUỐC SINH HỌC Ở BÊNHH NHÂN VIÊM CộT SỐNG DÍNH KHOÓP TAI KHOA CO' XƯƠNG KHỚP BỆNH VIÊ̂N BACH MAI}

\section{TÓM TẮT}

Mục tiêu: Mô tả thưoc trạng sử dụng thuốc sinh học trong điều trị viêm cột sống dính khớp tại khoa Cơ Xương Khớp- Bệnh viện Bạch Mai. Đối tượng và phương pháp: Nghiên cứu mô tả cắt ngang tiến cứu kết hợp hồi cứu trên 161 bệnh nhân viêm cột sống dính khớp (VCSDK) có dùng thuốc sinh hoc tai đia điểm nghiên cứu từ 01/2018 đến 7/2021. Kết quả: Thuốc sinh hoc hay được chon đâu tiên là nhóm thuốc thuộc nhóm kháng TNF-a $(69,6 \%)$ và thuốc thuộc nhóm kháng IL-17 là Secukinumab chiếm 30,4\%. Có 27,3\% bệnh nhân chuyển sang thuốc sinh học khác. Tỉ lê tuân thủ điều trị là $26,1 \%$. Lý do hàng đâuu của không tuân thủ điêu trị là: kinh tế $(35,2 \%)$ và đáp ứng tốt $(31,8 \%)$, đai dịch COVID-19 $(17,6 \%)$; của giân liều là đáp ứng tốt $(66,3 \%)$, kinh tế $(12,8 \%)$, đại dịch Covid-19 $(10,4 \%)$; của dừng thuốc phần lớn là do lý do kinh tế chiếm $50 \%$, các lý do khác: tác dung phụ $(14,3 \%)$, đại dịch Covid-19 (12,2\%); và của đổi thuốc là không đáp ứng thứ phát (34\%), không đáp ứng nguyên phát (24\%) và tác dụng phụ của thuốc $(20 \%)$. Kết luân: Thuốc sinh học được ưu tiên điều trị là các thuốc thuộc nhóm kháng TNF-a. Tỷ lệ bệnh nhẩn tuân thủ điều trị còn thấp. Lý do không tuân thủ hàng đầu

${ }^{1}$ Trường Đại học Y Hà Nội

${ }^{2}$ Bênh viên Bach Mai

Chịu trách nhiệm chính: Nguyễn Ngọc Trung

Email: drtrungtstl@gmail.com

Ngày nhận bài: 2.8.2021

Ngày phản biên khoa hoc: 1.10 .2021

Ngày duyệt bài: 8.10.2021 là kinh tế, tiếp đến là do sự đáp ứng tốt trong quá trình điều tri và ảnh hưởng của đai dich Covid-19. Các nguyên nhân: kinh tế, ảnh hưởng của đại dịch Covid19, hết thuốc, tác dung phụ và không đáp ứng vớ thuốc sinh học là những lý do chính khiến cho bệnh nhân đổi thuốc hoăc ngừng thuốc trong quá trình điều tri.

Tư khóa: viểm cột sống dính khớp, thuốc sinh học, tuân thủ điều trị.

\section{SUMMARY}

CURRENT STATUS OF BIOLOGICAL TREATMENT IN ANKYLOSING SPONDYLITIS PATIENT AT THE DEPARTMENT OF RHEUMATOLOGY - BACH MAI HOSPITAL

Objective: Describe the status of using biological drugs in treatment of ankylosing spondylitis at the Department of Rheumatology in Bach Mai Hospital. Subjects and methods: A prospective crosssectional descriptive combined with retrospective study on 161 ankylosing spondylitis patients who used biological drugs at the study site from January 2018 to July 2021. Results: The first choice biological drug was belonging to tumour necrosis factor inhibitors (TNFi) $(69,6 \%)$ and another drug in the class of antiIL-17 was Secukinumab (30,4\%). There was $27,3 \%$ of patients switched to other biologic drugs. The adherence rate was $26,1 \%$. The leading reasons for non-adherence were: economy $(35,2 \%)$ and good response $(31,8 \%)$, the Covid-19 pandemic $(17,6 \%)$; of dose dilatation were good response $(66,3 \%)$, economy $(12,8 \%)$, the Covid-19 pandemic $(12,2 \%)$ and out of drugs $(1,6 \%)$; the causes of drug discontinuation were largely due to economic reasons accounting for $50 \%$ 